\title{
Spectrophotometric Determination of Oxalic Acid in Dietary Sources Through Catalytic Titration with Hexavalent Chromium
}

\author{
Woinshet Kassie $^{1} \quad$ Alemayehu P. Washe ${ }^{2} \quad$ Hailemariam Etsay ${ }^{2 *}$ \\ 1.Department of Chemistry, Oda Bultum University \\ 2. Department of Chemistry, Hawassa University, P.O. Box 5
}

\begin{abstract}
Excess oxalic acid is thought to be a key factor of kidney stone formation in humans. Thus its level in food stuffs should be monitored. In this study, a new spectrophotometric titration method was developed for the determination of oxalic acid (OA) in dietary sources through reaction with hexavalent chromium in presence of Mn (II) as a catalyst. Cr (VI) was used as UV-active material and the determination of OA was based on the decrease in absorbance of the $\mathrm{Cr}(\mathrm{VI})$ solution as a result of its reaction with OA. Factors influencing the reduction of $\mathrm{Cr}(\mathrm{VI})$, including incubation time, solution $\mathrm{pH}$ and background concentration ratio have been optimized. The results showed that the amount of oxalic acid $(\mathrm{mg} / \mathrm{g})$ in vegetable samples of Ethiopian collared green (raw and cooked), cabbage (raw and cooked), lettuce (raw),beetroot (raw), pineapple (before ripe and fully ripe) and mango (before ripe and fully ripe) were $24.15 \pm 0.565$ and $12.05 \pm 0.183,16.72 \pm 0.388$ and 9.50 $\pm 0.424,14.44 \pm 0.183,15.77 \pm 0.175,23.08 \pm 0.212$ and $18.31 \pm 0.424,6.75 \pm 0.212$ and $1.18 \pm 0.169$ respectively. Ethiopian collared green (Brassica oleraceavar. acephala) contained highest concentration of oxalate, but it was reduced by $50 \%$ after boiling for ten minute. The level of oxalate content in the analyzed fruit samples was found to decrease with increasing growing stage or state of ripeness. All studied food samples contained relatively moderate amounts of total oxalate $(<25 \mathrm{mg} / \mathrm{g}$ dry weight $)$ and are safe for human consumption especially when cooked or fully ripe. A very good correlation was observed when the results from the current method and standard method (HPLC) were compared. In conclusion, the current method can successfully be used for determination of OA in fruit and vegetable samples.
\end{abstract}

Keywords: Spectrophotometric titration, Hexavalent Chromium, Oxalic acid, HPLC.

DOI: $10.7176 / F S Q M / 83-04$

\section{Introduction}

Oxalic acid is a product of protein metabolism and is one of the important nutrients in the human diet. Common dietary sources of oxalic acid include spinach (Spinacia oleracea), beet leaves, vegetables, chocolate, tea (Camellia sinensis) etc. [1]. Soluble oxalic acid can be found as potassium, sodium, or ammonium oxalate salts. Its levels depend on the type and age of plant tissue as well as growth rate [2-4].

Oxalic acid is of scientific interest as a result of its antinutritive properties and association with kidney stone formation at high concentrations. Oxalic acid (or its dissociated form oxalate) cause decreased bioavailability of other nutrients and increased risk of kidney stone formation due to production of insoluble salts with dietary cations (mainly calcium) thus rendering the complex unavailable for adsorption and assimilation (antinutritive effect). Adsorbed oxalic acid can also cause assimilated calcium to be precipitated as insoluble salts accumulating in the renal glomeruli, leading to renal disorder. Evidences showed that about $75 \%$ of all kidney stones are composed primarily of calcium oxalate and hyperoxaluria is a primary risk factor for this disorder [510]. Determination of oxalate in clinical samples such as urine and blood has thus served as a basis in diagnosis and medical management of primary and secondary hyperoxaluria, urinary stone disease [ $[7,11]$.

Reductions of oxalates in the diet can be achieved by avoiding foods which are known to contain high levels of oxalate and by processing the foods in different ways. Soaking and boiling are efficient way of reducing the level of oxalate in food if the cooking water is discarded [11]. Likewise, addition of calcium can make soluble oxalate unavailable for absorption by binding- complex [12]. By consuming a food high in calcium together with foods containing oxalates, the insoluble calcium oxalate formed passes through the intestinal tract without absorption and thereby decreases the risk of kidney stone formation. Other studies have shown that fat and oils can bind oxalate and thereby make soluble oxalates unavailable for absorption [13].

The oxalate determination by AOAC (1984) [14] method was based on calcium oxalate precipitation. It has some limitation in terms of sensitivity, precision and time consumption. Spectrometric methods have received considerable attention because of the significant advantages in the determination of several analyte at trace levels, especially when only a simple photometer is required as the main instrument. Spectrophotometric methods based on the inhabitation or the catalytic effect of OA on the rate of a definite reaction system has been reported $[5,7$, $11,12]$.

This paper describes a simple and sensitive method for determination of oxalic acid in selected green leafy vegetables (beetroot, cabbage, Ethiopian collared green and lettuce) and stony fruits (mango and pineapple) based on spectrophotometric titration of $\mathrm{Cr}$ (VI) by the analyte in the presence of Mn (II) as a catalyst. The 
decrease in absorbance of the Cr (VI) was measured at $350 \mathrm{~nm}$ under optimized conditions. Method validation was carried out through determination of \% recovery and comparison with standard technique-high-performance liquid chromatography (HPLC) [15-18].

\section{Materials and Methods}

Chemicals and Reagents

All the chemicals used were of analytical grade reagent and used without further purification. $98 \% \mathrm{H}_{2} \mathrm{SO}_{4}$ (analytical reagent, England), $37 \% \mathrm{HCl}$ (Aldrich, Germany), LC-MS-grade octanol (Sigma, Milwaukee, USA), $50 \mathrm{mM} \mathrm{KH}_{2} \mathrm{PO}_{4}$ as mobile phase and $\mathrm{CH}_{3} \mathrm{CN}$ as organic solvent modifier were used. $\mathrm{MnCl}_{2}$ as source of divalent manganese (used as catalyst) and $\mathrm{K}_{2} \mathrm{Cr}_{2} \mathrm{O}_{7}$ as source of hexavalent chromium (used as oxidant) (analytical reagent, Germany) was used during reduction of hexavalent chromium by oxalic acid. $\mathrm{H}_{3} \mathrm{PO}_{4}$ was used to adjust the initial $\mathrm{pH}$ of a solution to desired values during UV-Vis analysis. Distilled water was used for sample preparation, dilution and rinsing apparatus before sample solution preparation.

\section{Apparatus and Instrument}

UV-Vis spectrophotometer equipped with deuterium lamp, Quartz cuvette with $1 \mathrm{~cm}$ cell of path length (model CECIL 121, England) ], orbital shaker, shaking bottle, glassware's, $0.045 \gamma \mathrm{m}$ syringe filter, A refrigerator (Hitachi, Germany), digital analytical balance (ADAM, Model AFP-110L, England). Drying oven (Digit heat, J. P. Selecta, Germany), Digital pH, measuring cylinders (Duran, Germany), dropper, pipettes and micro pipettes (Pyrex, England), Volumetric flasks with stopper (Pyrex, England), Pyrex beaker to boil the real sample, aluminum foil, Whatman 541 filter paper, knife, spatula, wash bottle, hot plate, Pestle and mortar were used for grinding and homogenizing the fruit and vegetables samples. An Agilent technology (1200 infinity series) HPLC equipped with UV detector was used for determination of oxalate content.

\section{Sample collection}

Samples were collected systematically from common market and fruit juice shops of Hawassa town. The fully ripe and unripe stony fruits of pineapple and mango were purchased from fruit juice shops in Hawassa, whereas the green leafy vegetable of lettuce, beetroot and cabbage and Ethiopian collared green were collected from Hawassa common market.

\section{Sample preparation}

The vegetables were washed with tap water and edible parts of all the vegetables were selected. The raw portion of these samples were boiled for ten minute at room temperature and then cooled in cold water; the water was discarded. All of the vegetables except beetroot were vacuum dried for 24 hour at $50{ }^{\circ} \mathrm{C}$ and then vacuum packed until analysis. The vacuum dried materials were then ground into a fine powder by using mortar and pestle. After the edible part of the raw lettuce and beetroot was selected, it was chopped in to pieces then it was vacuum dried at $55{ }^{\circ} \mathrm{C}$ for two days. The vacuum dried materials were then ground into a fine powder by using mortar and pestle. Mango and pineapple were washed with tap water and the flesh part of the fruits was selected using knife then sliced in to smaller pieces and dried in an oven at $55{ }^{\circ} \mathrm{C}$ for 5 days. After the dried samples were ground into powdery form using mortar and pestle. The powdered samples were sieved to obtain fine powder which was later digested. Finally the powdered materials were sealed in an aluminum foil bag until analysis could commence.

\section{Sample extraction for OA determination using UV-Vis Spectrophotometer method}

$1 \mathrm{~g}$ dried sample was weighed and boil in $150 \mathrm{ml}$ water containing $27.5 \mathrm{ml} 6 \mathrm{M} \mathrm{HCl}$ plus 2 drops of octanol for $25 \mathrm{~min}$ in beaker. The mixture was cooled, transferred to a $250 \mathrm{ml}$ volumetric flask and made up to mark. The mixture was then filtered through Whatman 541 filter paper. A volume of $10 \mathbf{m l}$ of this filtrate was evaporated at $40-45^{\circ} \mathrm{C}$ in a vacuum oven and re-dissolved in $10 \mathrm{ml}$ of $0.01 \mathrm{M} \mathrm{H}_{2} \mathrm{SO}_{4}$. Then $0.5 \mathrm{mM} \mathrm{K}_{2} \mathrm{Cr}_{2} \mathrm{O}_{7}$ and $0.25 \mathrm{mM}$ $\mathrm{MnCl}_{2}$ was prepared in $250 \mathrm{ml}$ volumetric flask; this solution was the background (blank) solution during OA standard solution. $1 \mathrm{ml}$ from each extracted sample and $9 \mathrm{ml}$ from the blank solution, a total of $10 \mathrm{ml}$ was taken for each sample and incubated for $60 \mathrm{~min}$. Finally the total OA in the sample was analyzed using a UV-Vis Spectrophotometer [19]. 


\section{Sample Extraction for OA determination using HPLC method}

$4 \mathrm{~g}$ of homogenized sample was weighed in to a $250 \mathrm{ml}$ shaking bottle and $50 \mathrm{ml}$ of $2 \mathrm{~N} \mathrm{HCl}$ was added. The content of the bottle was shaking for $50 \mathrm{~min}$ at $250 \mathrm{rpm}$ then it was removed from the shaker and $50 \mathrm{ml} \mathrm{HPLC}$ grade $\mathrm{H}_{2} \mathrm{O}$ was added, then appropriate volume of extract was filtered through $0.45 \mu \mathrm{m}$ syringe filter. The filtrate was transferred in to a $2 \mathrm{ml}$ vial and the vial was capped. Finally, the total oxalate in the sample was analyzed using HPLC method.

\section{Data analysis}

As the study aimed to determine OA in dietary sources using UV-Vis spectrophotometer and HPLC method data obtained were analyzed by a computer program to analyze tabulated data using Microsoft Excel 2007 and origin 8 Software. T-test was used to assess the significance difference between fully ripe and unripe fruits and also raw and cooked vegetables.

\section{Results and Discussion}

\section{Method development and optimization}

In this study the amount of total oxalic acid in selected dietary sources (leafy vegetables and stony fruits) was determined using indirect UV-Vis method through Catalytic Titration with Cr (VI). Cr (VI) was used as UVactive material and the determination of OA was based on the decrease in absorbance of the Cr (VI) solution as a result of its reaction with OA in presence of Mn (II) as a catalyst. When the Cr (VI) was reacted with oxalic acid in the presence of Mn (II), it was reduced and gradually eliminated from the reaction. The advantage of this method is that it does not necessarily require completion of the reaction. Because, the decrease in absorbance of the solution after a specified duration of incubation depends on the residual concentration of oxidant which is used as limiting reactant (analyte). The kinetics of the reaction depends on the concentrations of all reactant and catalyst as well as other experimental variable including $\mathrm{pH}$, and Temperature. The reaction of $\mathrm{Cr}$ (VI) with OA was catalyzed by $\mathrm{Mn}$ (II), but the amount of $\mathrm{Mn}$ (II) required to complete the reaction depends on how much $\mathrm{Cr}$ (VI) is present in the sample and thus affects the rate of reaction. Therefore, for successful application of the current method, it was important to optimize the experimental variables including oxidant to catalyst ratio, $\mathrm{pH}$, and contact time. Prior to anything, however, it was important to determine whether a significant change in absorbance of the oxidant solution can be observed at high enough concentration of the analyte during incubation the two for different period of time. This was successful and the result is indicated in Figure 1 (A). In absence of the analyte (OA), the absorbance of the oxidant solution containing the catalysts remained practically unchanged. However, a progressive decrease in absorbance was observed in presence of OA. This laid a basis to envisage that under optimized conditions, the decrease in absorbance could have quantitative relation with concentration of OA. We first optimized the oxidant (Cr (VI)) to catalyst (Mn (II)) ratio by keeping contact time constant (30 $\mathrm{min})$ and judiciously varying $\mathrm{Cr}$ (VI) and $\mathrm{Mn}$ (II) ratio while recording change in absorbance with respect each selected concentration of OA as shown in Figure 1 (B). The reaction was carried out in dark at 25 ${ }^{\circ} \mathrm{C}$. When fixing the oxidant and increase the catalyst from 1:0.25 to $1: 0.5$, the instrument can't detect small concentrations of oxalic acid such as $0.01 \mathrm{mM}, 0.1 \mathrm{mM}$ and $0.5 \mathrm{mM}$. It can detect oxalic acid concentration greater than $1 \mathrm{mM}$. However, 0.5:0.25 $\mathrm{mM}$ oxidant/catalyst ratio can detect small concentrations of oxalic acid and assured linearity of the calibration curve with correlation coefficient of 0.994 . When diluting 0.5:0.25 oxidant/catalyst ratios to $0.05: 0.025$ oxidant/catalyst ratios the $\mathrm{Cr}$ (VI) reduction was finished after oxalic acid concentration of $0.1 \mathrm{mM}$ and it became the limiting reagent. That means in the reaction of $\mathrm{Cr}$ (VI) and Oxalic acid in the presence of $\mathrm{Mn}$ (II), the $\mathrm{Cr}$ (VI) reduced readily and the oxalic acid was remained alone. This resulted as concentration of oxalic acid increase; the absorbance reading became equal or stable. Since a better sensitivity (slope of the curve) quantitative response of the instrumental response (change in absorbance) to concentration of analyte was observed when the Cr (VI): Mn (II) ratio was 0.5:0.025, it was used as the best background ratio. This concentration ratio is consistence with previous results [20]. 

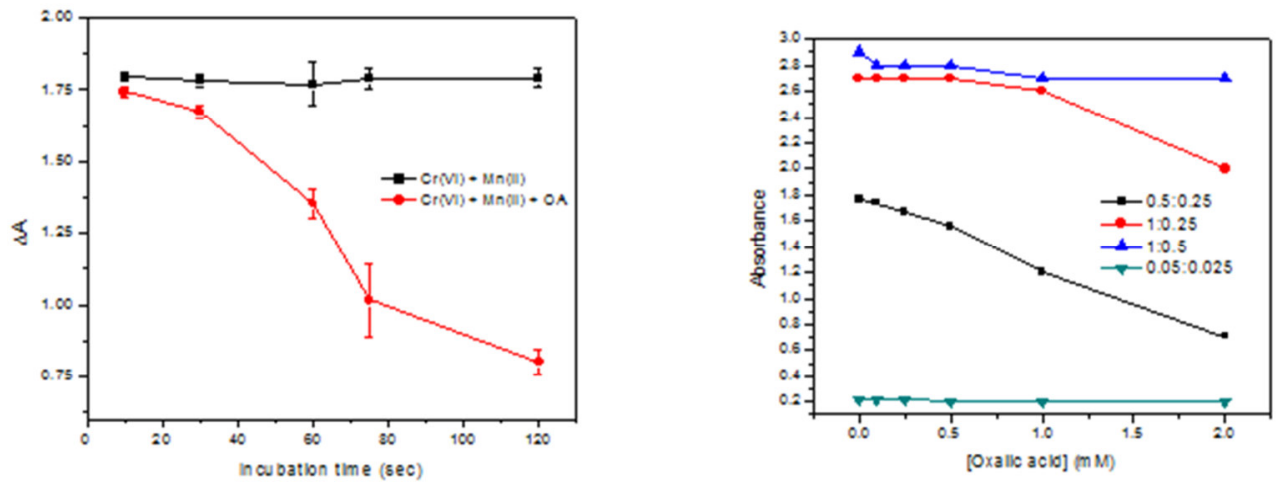

Figure 1 (A) Change in absorbance against different incubation time of background solution in absence (a) and presence of Oxalic acid (b); effect of (B) oxidant/catalyst ratio

\section{Effect of reaction time}

When oxalic acid was reacted with $\mathrm{Cr}$ (VI) in the presence of Mn (II), the reduction efficiency was depend on reaction time. So, fixing the reaction time that the oxidant can reduce and knowing completion time of the reaction was valid. After mixing same optimized combination of oxidant/catalyst with different concentrations $\mathrm{OA}$, the reaction mixtures were incubated for 10,30, 60, 90 and 120 minutes and absorbance measurements were performed at each time. The result is indicated in Figure 2. As can be seen in Figure 2 the reduction of $\mathrm{Cr}(\mathrm{VI})$ was related to the slope of calibration curve and the reaction time. As the reaction time increase, the $\mathrm{Cr}$ (VI) became reduced and the graph became sloppier. At 10 minute the absorbance result does not change while concentration of oxalic acid increased and it was less sloppy. After 30 minute the $\mathrm{Cr}$ (VI) starts to reduce (the absorbance became decreased to some extent) and the curve became sloppier than previous one. Even though, the calibration curve of all measurements showed reduction of $\mathrm{Cr}(\mathrm{VI})$, a more sensitive response was observed after 60 minute. Although a slight improvement in sensitivity could be observed at higher contact time, 60 min was chosen based on time economy.

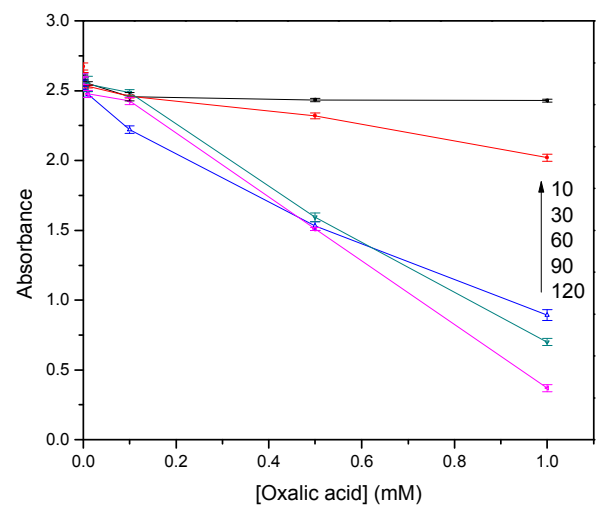

Figure 2. Effect of reaction time on reduction of $\mathrm{Cr}(\mathrm{VI})$ by $\mathrm{OA}$

\section{Effect of PH}

In order to determine the best $\mathrm{pH}$ at which a faster reduction of $\mathrm{Cr}(\mathrm{VI})$ by $\mathrm{OA}$ can be observed, we carried out the reaction at previously optimized contact time and oxidant: catalyst ratio at $\mathrm{pH} 3,5$ and 9 . The result is indicated in Figure 3. 


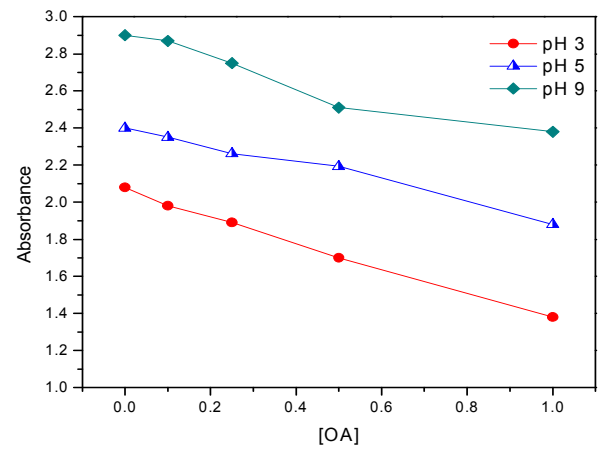

Figure 3. Effect of $\mathrm{pH}$ on reduction of $\mathrm{Cr}(\mathrm{VI})$ by oxalic acid

The best reduction of $\mathrm{Cr}$ (VI) was observed at PH 3 while oxalic acid concentration was increased. That means the reduction works in acidic media. Cr (VI) has slow reduction at slightly acidic conditions (pH 5). In basic media ( $\mathrm{pH}$ 9) quantitative reduction of $\mathrm{Cr}$ (VI) was not observed. Therefore, $\mathrm{pH} 3$ was selected.

\section{Interference study}

To study the selectivity of the proposed method, the effect of potential interfering substances that could exist in the studied fruit/vegetable samples were considered. For this purpose, maleic acid (MA) was considered because of its presence in most fruits and vegetables [21, 22]. The effect of MA on the absorbance of the Cr (VI) and OA mixture was studied by recording absorbance of $\mathrm{Cr}$ (VI) and OA mixture in presence and absence of MA. The presence of $1 \mathrm{mM}$ MA could cause a difference of only 0.002 in absorbance. Due to this the developed method can be successfully applied for the detection of OA in the presence of other interfering species such as MA.

Table 1.The change in absorbance of chromium in absence and presence maleic acid

\begin{tabular}{|c|c|c|c|c|c|}
\hline $\mathbf{S} / \mathbf{N}$ & $\mathbf{C r}(\mathbf{V I}) \mathbf{( m M )}$ & $\mathbf{M n} \mathbf{( I I )}(\mathbf{m M})$ & $\mathbf{O A}(\mathbf{m M})$ & $\mathbf{M A}(\mathbf{m M})$ & $\Delta \mathbf{A}$ \\
\hline 1 & 0.5 & 0.25 & 1 & 0 & 0.182 \\
\hline 2 & 0.5 & 0.25 & 0 & 1 & 0.05 \\
\hline 3 & 0.5 & 0.25 & 1 & 0.1 & 0.118 \\
\hline 4 & 0.5 & 0.25 & 1 & 0.5 & 0.169 \\
\hline 5 & 0.5 & 0.25 & 1 & 0.180 \\
\hline
\end{tabular}

\section{Determination of $\mathrm{OA}$ in real samples}

Calibration curve of change in absorbance against standard concentrations of OA was constructed using 0.01 , $0.25,0.5,1$ and $2 \mathrm{mM}$. A linear relationship was observed between changes in absorbance of the background solution in presence of $\mathrm{OA}$ in the studied range with linear regression equation of $\mathrm{y}=0.475 \mathrm{x}+0.015$ with $\mathrm{R}^{2}=$ 0.997 was recorded. Finally the amount of OA in the sample was determined from the calibration curve. The result is summarized in Table 2. The values of LOD and LOQ $(n=5)$ were determined as the analyte concentration corresponding to 3 times of the standard deviation of the reagent blank divided by slope of the calibration curve (LOD) and 10 times standard deviation divided by the slope of the calibration curve (LOQ). Accordingly, the LOD and LOQ of the method were 0.0012 and $0.004 \mathrm{mM}$.

Table 2. Oxalic Acid concentration in selected dietary source samples (Mean \pm S.D, $n=3$ )

\begin{tabular}{|c|c|c|c|c|c|}
\hline S/N & Scientific name & Common name & Status & Abbreviated name & OA (mg/g ) \\
\hline 1 & Brassica & \multirow{2}{*}{$\begin{array}{c}\text { Ethiopian collared } \\
\text { green }\end{array}$} & Raw & RCG & $24.15 \pm 0.565$ \\
\cline { 4 - 6 } & oleraceavar.acephala & Cooked & CCG & $12.05 \pm 0.183$ \\
\hline 2 & $\begin{array}{c}\text { Brassica oleracea Var } \\
\text { capitata }\end{array}$ & Cabbage & Raw & RC & $16.72 \pm 0.388$ \\
\cline { 4 - 6 } & & Cooked & CC & $9.5 \pm 0.424$ \\
\hline 3 & Lactuca sativa & Lettuce & Raw & Le & $14.44 \pm 0.183$ \\
\hline 4 & Beta vulgaris & Beetroot & Raw & Be & $15.77 \pm 0.175$ \\
\hline 5 & Ananas comosus & Pineapple & Unripe & PBR & $23.08 \pm 0.212$ \\
\cline { 3 - 5 } & & & Fully ripe & PFR & $18.31 \pm 0.424$ \\
\hline 6 & Mangiferaindica & \multirow{2}{*}{ Mango } & Unripe & MBR & $6.75 \pm 0.212$ \\
\cline { 3 - 5 } & & & Fully ripe & MFR & $1.18 \pm 0.169$ \\
\hline
\end{tabular}

The concentrations of the OA along the fully ripe fruit sample showed a decrease in concentration as compared to unripe fruit sample and this might be the result of an increase in membrane permeability which allows acids to be stored in the respiring cells, formation of salts of OA, reduction in the amounts of acid translocate from the leaves, reduced ability of fruits to synthesize organic acids with fruit maturity, translocation 
into sugars and dilution effect due to the increase in the volume of fruit as previously reported in the literature [23]. The high concentrations of OA in raw vegetables were also recorded as compared to values obtained from cooked vegetables. This indicated that cooking can reduce the level of OA in vegetable.

\section{HPLC Chromatogram of OA standard for analyzing mango and Ethiopian collared green}

Chromatogram of OA standard was recorded in order to determine the retention time that the chromatographic peak was eluted. The chromatographic peak for the OA standard for analyzing mango and Ethiopian collared green was eluted with a retention time of 2.039 and 7.485 minute respectively so the sample peak also expected to elute at this retention time. Experimental conditions are shown in Table 3.

Table 3. HPLC Chromatographic conditions (parameters) for analyzing OA standards

\begin{tabular}{|l|c|c|}
\hline \multicolumn{2}{|c|}{ Chromatographic condition one } & Chromatographic condition two \\
\hline Column & $\begin{array}{c}\text { Agilent poroshell-C18 } 250 \times 4.6 \mathrm{~mm}, \\
2.7 \mu \mathrm{m} \text { connected series }\end{array}$ & $\begin{array}{c}\text { Agilent poroshell-C18 100x2.1mm, } 2.7 \\
\mu m \text { connected series }\end{array}$ \\
\hline Mobile phase & $50 \mathrm{mM} \mathrm{KH}_{2} \mathrm{PO}_{4}, \mathrm{PH} 2.8$ with $\mathrm{H}_{3} \mathrm{PO}_{4}$ & $50 \mathrm{mMKH}_{2} \mathrm{PO}_{4}, \mathrm{pH} 2.8 \mathrm{with}_{3} \mathrm{PO}_{4}$ \\
\hline Analysis Time & 25 minute & $25 \mathrm{minute}$ \\
\hline Flow rate & $1 \mathrm{ml} / \mathrm{min}$. & $0.6 \mathrm{ml} / \mathrm{min}$. \\
\hline Column Temperature & $50^{\circ} \mathrm{c}$ & $20^{\circ} \mathrm{c}$ \\
\hline Injection Volume & $5 \mu l$ & $5 \mu 1$ \\
\hline Detector & $\mathrm{UV}$ with $210 \mathrm{~nm}$ & $\mathrm{UV}$ with $210 \mathrm{~nm}$ \\
\hline
\end{tabular}

\section{Determination of OA in real samples using HPLC method}

To determine the amount of OA in mango sample and Ethiopian collared green using HPLC method, calibration curve of OA standards were constructed under their perspective chromatographic condition. To determine the concentration of OA in mango sample, standard working serials of concentration of $0.1,0.15,0.2,0.5 \mathrm{and} 1 \mathrm{mg} /$ $\mathrm{ml}$ in $2 \mathrm{~N} \mathrm{HCl}$ were prepared and their observed peak areas were 164.342, 246.393, 330.555, 780.409 and 1509.965 respectively. Similarly to determine the concentration of OA in Ethiopian collared green, four standard working serials of concentration $0.1,0.2,0.5$ and $1 \mathrm{mg} / \mathrm{ml}$ were prepared and the observed peak areas were 198.245, 444.323, 1000.592 and 1910.043 respectively. In this study OA standard solution was analyzed in triplicate and mean values were reported. The first chromatographic condition which was leveled as 'Chromatographic condition one' was used for analyzing the mango sample and the second chromatographic condition which was leveled as 'Chromatographic condition two' was used for analyzing the Ethiopian collared green. The standard curves were plotted to compute the regression equations and the concentration of oxalate from each sample solution was calculated from the equation of the corresponding standard curve. The results of the OA content indicated in Table 4.

Table 4. Total oxalic acid content of mango and Ethiopian collared green.

\begin{tabular}{|l|l|l|l|l|}
\hline S/N & Type of sample & Status & $\begin{array}{l}\text { Abbreviated } \\
\text { name }\end{array}$ & $\begin{array}{l}\text { Total } \\
(\mathbf{m g} / \mathbf{g})\end{array}$ \\
\hline 1 & & & Ethiopian collared green(Brassica \\
oleraceavar.acephala) & Raw & RCG & 20.00 \\
\cline { 3 - 5 } & Cooked & CCG & 9.58 \\
\hline 2 & Mango(Mangiferaindica) & Fully ripe & MFR & 0.74 \\
\cline { 3 - 5 } & & Before ripe & MBR & 3.18 \\
\hline
\end{tabular}

The analyzed green leafy vegetables and stony fruits in this study contained relatively low to moderate amounts of total oxalate that were less than $25 \mathrm{mg} / \mathrm{g}$ (Table 2 and Table 4). These results suggest that, the consumer should limit the use of these foods to an optimum per day [24]. However, the analyzed mango sample in this study is safe for consumption with little or no effect on the body system since it contains small amount of oxalate; less than $10 \mathrm{mg} / \mathrm{g}$. In the present study, mangos were reported to contain $0.74 \mathrm{mg}$ and $3.18 \mathrm{mg}$ of total oxalate/g of dry weight for MFR and MBR, respectively. However, in the literature [25] the amount of oxalate in fully ripe mango was $1 \mathrm{mg} / \mathrm{g}$ of when analyzed with AOAC 1999 method and $1.07 \mathrm{mg} / \mathrm{g}$ of when analyzed with enzymatic method (Kit). The variation in oxalate values in different sources of plants can be affected by factors such as soil quality, climate condition and different state of fruit ripeness [26]. In addition, discrepancies could also be due to differences in preparation of the samples and analytical techniques. Interestingly, the level of OA was found to depend on the level of ripeness and cooking. Its level was higher in unripe and raw samples. The data in Table 4 is also reinforced by the corresponding decrease in the area under peak or intensities of the chromatograms (Figure 4). As can be seen in Figure 4, a more intense (higher area) peak was observed with unripe mango (Figure 4 (a) versus (b)) and raw vegetable (Figure 4 (c) versus (d)).

Percentage of oxalate loss due to cooking was calculated as 100-\%TR (True Retention) [27]. 


\section{$\% T R=\frac{\text { oxalate content per } g \text { of cooked food } \times g \text { of food after cooking } \times 100}{\text { Oxalate coalntent per } g \text { of raw food } \times \text { of of food before cooking }}$}

Therefore, the soluble oxalates in cabbage (GG) were reduced by $30.99 \%$ after boiling $5 \mathrm{~min}$. However, the soluble oxalate levels in gurage gomen cooked (GGC) that was then boiled was $9.58 \mathrm{mg} / \mathrm{g}$. These data suggest that household cooking is a very effective method to reduced soluble oxalate levels. Savage et al. (2000) [18] showed that boiling resulted in significant loss of soluble oxalates of some New Zealand foods such as spinach (Spinacia oleracea), silver beet (Beta vulgaris v.cicla) and rhubarb (Rheum rhaponticum).

Loss of oxalates in various vegetables is likely due to their leaching loss in cooking water. Other authors also reported a significant percentage loss of $\mathrm{OA}$ in different food items by cooking. Wanasundera and Ravindran (1992) [28] reported 40-50\% loss of total oxalates when two kinds of yam tubers (Dioscoreaalata and D. esculenta) were boiled compared to steamed (20-25\%). Judprason et al. (2006) [29] showed percentage loss ranging from $18 \%$ in coconut heart top stems (Cocos nucifera Linn.) to $76 \%$ in A. pennata. Therefore, the present findings are consistence with previous reports and reinforced the importance cooking as a strategy to reduce $\mathrm{OA}$ level in vegetables.
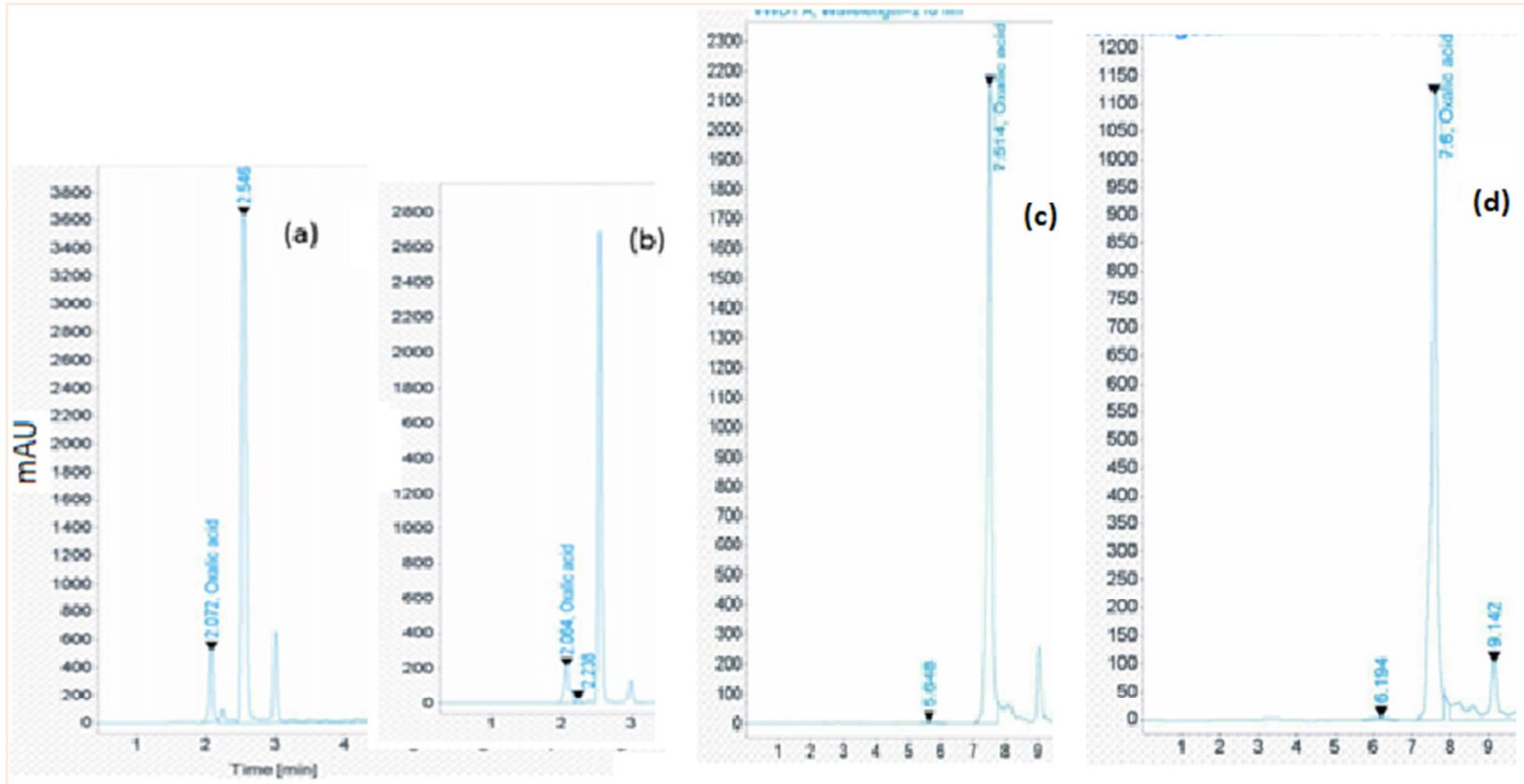

Figure 4. HPLC Chromatogram of (a) Mango Unripe and (b) Mango fully ripe, (c) Raw collared green cabbage and (d) Cooked collared green cabbage.

\section{Comparison of the two methods}

In the present study, the oxalate content that was analyzed by UV-Vis method yielded more total oxalate than HPLC method for both vegetables and fruit samples. The discrepancy of the results between the two methods might be due the difference of the extraction procedure, sensitivity of the analytical technique and effect of different experimental variables that we used for analysis. In both methods, the amount of total oxalate in cooked vegetable samples and fully ripe fruit samples were lower than raw vegetable samples and unripe fruit samples. Thus, the current method can fairly be used for the determination of OA in fruit and vegetable samples.

\section{Conclusions}

In this study, a new spectrophotometric method was successfully developed for the determination of oxalate content of selected food samples including mango and pineapple from stony fruits and beetroot, lettuce, Ethiopian collared green and cabbage from green leafy vegetables through catalytic titration with hexavalent chromium in presence of Mn (II) as a catalyst. A fairly good correlation was observed between the results from current method and standard method (HPLC). The studied samples contained relatively low to moderate amount of total oxalate $(<25 \mathrm{mg} / \mathrm{g}$ dry weight). Out of ten foods studied, Ethiopian collared green (Brassica oleraceavar.acephala) contained highest concentration of oxalate, but it was reduced by $50 \%$ after boiling for ten minute. Therefore, it can be concluded that the studied vegetable samples are safe for human consumption especially after cooking. The level of oxalate content in the analyzed fruit samples was found to decrease with increasing growing stage or state of ripeness. Fully ripe fruits contained lower concentration of oxalate than unripe fruits (at $\mathrm{p}=0.05$, there is a significance difference between the fully and unripe fruits). 


\section{References}

1. McCann L, ed. Pocket Guide to Nutritional Assessment of the Patient with Chronic Kidney Disease. $4^{\text {th }}$ Ed. New York, NY: National Kidney Foundation Council on Renal Nutrition; 2009. Online errata: http://www.kidney.org/professionals/CRN/pocketGuide/pdf/7-14-09 Errata $4^{\text {th }}$ Ed Nutrition Pocket Guide.pdf

2. Albihn, P.B.E. and G.P. Savage. 2001. The effect of cooking on the location and concentration of oxalate in three cultivars of New Zealandgrown oca (Oxalis tuberosaMol). J. Sci. Food Agr. 81:1027-1033.

3. Kaminishi, A. and N. Kita. 2006. Seasonal change of nitrate and oxalate concentration in relation to the growth rate of spinach cultivars. Hort Science 41:1589-1595.

4. Morita, A., R. Suzuki, and H. Yokota. 2004. Effect of ammonium application on the oxalate content of tea plants (Camellia sinensis L.). Soil Sci. Plant Nutr. 50:763-769.

5. Bataille, P. and Fournier, A. (2001). Calcium supply in calcium lithiasis. Journal of Medical Nutrition. 37, 912

6. Brogren, M. and G. Savage. 2003. Bioavailability of soluble oxalate from spinach eaten with and without milk products. Asia Pac. J. Clin.Nutr. 12:219-224.

7. Holmes, R. P., Goodman, H. O. and Assimos, D. G. (2001). Contribution of dietary oxalate to urinary oxalate excretion.Kidney International. 59, 270-276.

8. Morris, J., P.A. Nakata, M. McConn, A. Brock, and K.D. Hirschi. 2007. Increased calcium bioavailability in mice fed genetically engineered plants lacking calcium oxalate. Plant Mol. Biol. 64:613-618.

9. Nakata, P.A. and M.M. McConn. 2006. A genetic mutation that reduces calcium oxalate content increases calcium availability in Medicagotruncatula. Funct. Plant Biol. 33:703-706.

10. Robertson, W.G. and B.E.C. Nordin. 1969. Activity products in urine. Proc. Renal Stone Res. Symp. p. 221232.

11. Chai, W. and Liebman, M. (2005a). Effect of different cooking methods on vegetable oxalate content.Journal of Agricultural and Food Chemistry. 53, 3027-3030.

12. Hanson, C. F., Frankos, V. H. and Thompson, W. O. (1989). Bioavailability of oxalic acid from spinach, sugar beet fiber and a solution of sodium oxalate consumed by female volunteers.Food Chemistry Toxicology. 27, 181-184.

13. Liebman, M., Harvey, E. and Chai, W. (1999). Olestra and fat inhibit oxalate absorption. Nutration Research. $19,1277-1285$.

14. AOAC (2002). Official methods of analyses of AOAC International, Gathersberg, MD, USA: AOAC International.

15. Holloway, W. D., Argall, M. E., Jealous, W. T., Lee, J. A., \& Bradbury, J. H. (1989). Organic acids and calcium oxalate in tropical root crops. Journal of Agricultural and. Food Chemistry,37, 337-341. http://dx.doi.org/10.1021/jf00086a014

16. Utzman, S. (1993). Improved analysis of process liquors for the pulp and paper industry by ion chromatography. Journal of Chromatography A. 640, 287-292.

17. Brega, A., Quadri, A., Vitta, P., Prandini, P., Wei, J.Q., Lucarelli, C. (1992). Improved HPLC determination of plasma and urine oxalic acid in the clinical diagnostic laboratory. Journal of Liquid Chromatography. 15 (3), 501-511.

18. Savage, G.P., L. Vanhanen, S.M. Mason, and A.B. Ross. 2000. Effect of cooking on the soluble and insoluble oxalate content of some New Zealand foods. J. Food Compost. Anal. 13:201-206.

19. Popoola, O. E., Doherty, V. F., Odusami, J. O and Durowoju, O. S. (2014). Oxalate content of some Nigerian tubers using titrimetric and UV-spectrophotometric methods. Acadamic Journal of Agricultural Research. 2, 054-057.

20. Wrobel, K., Escobosa, ARC., Ibarra, AAG., Garcia, MM., Barrientos, EY., Wrobel, K. (2015). Mechanistic insight into chromium(VI) reduction by oxalic acid in the presence of manganese(II). Journal of Hazardous Materials. 300, 144-152.

21. Deng, B. and Stone, A. T. (1996). Surface catalyzed Cr (VI) reduction: Reactivity comparisons of different organic reductants and different oxide surfaces. Environmental Science and Technology. 30, 2484-2491.

22. Fernandes, F., Valentao, P., Sousa, C., Pereira, J., Seabra, R. and Andrade, P. (2007). Chemical and antioxidative assessment of dietary turnip (Brassica rapavar. rapaL.).Food Chemistry.105, 1003-1010.

23. Justina, Y., Olukemi, A., Osukoya, O. O. and Adegoke, G. O. (2016). Nutritional and anti-nutritional compositions of processed Avocado (PerseaamericanaMill) seeds. Asian Journal of Plant Science and Research. 6, 6-12.

24. Verheij, E. W. M. and Coronel, R. E. (1992). Plant resources of south-east Asia No. 2, Edible fruits and nuts.Backhuys, the Netherlands. 6, 6-12.

25. Abdel-Moemin, A. R. (2014). Oxalate Content of Egyptian grown fruits and vegetables and daily common herbs. Journal of Food Research. 3, 561-569 
26. Libert, B. and Franceschi, V. R. (1987). Oxalate in crop plants. Journal of Agriculture and Food Chemistry. 35, 926-938.

27. Murphy, E.W., Criner, P.E., Gray, B.C. (1975). Comparisons of methods for calculating retentions of nutrients in cooked foods. Journal of Agricultural and Food Chemistry. 23, 1153-1157.

28. Wanasundera, J. P. D. and Ravindran, G. (1992). Effects of cooking on the nutrient and anti-nutrient contents of yam tubers (Dioscoreaalata and Dioscoreaesculenta).Food Chemistry. 45, 247-250.

29. Judprasong, K., Charoenkiatkul, S., Sungpuag, P., Vasanachitt, K., Nakjamanong, Y. (2006). Total and soluble oxalate contents in Thai vegetables, cereal grains and legume seeds and their changes after cooking. Journal of Food Composition and Analysis. 19, 340-347. 